\title{
Risk factors for infectious complications of ANCA-associated vasculitis: a cohort study

\author{
Liu Yang ${ }^{\dagger}$, Honglang Xie ${ }^{\dagger}$, Zhengzhao Liu, Yinghua Chen, Jinquan Wang, Haitao Zhang, Yongchun Ge \\ and Weixin $\mathrm{Hu}^{*}$
}

\begin{abstract}
Background: Severe infections are common complications of immunosuppressive treatment for antineutrophil cytoplasmic antibody (ANCA)-associated vasculitis (AAV) with renal involvement. We investigated the clinical characteristics and risk factors of severe infection in Chinese patients with AAV after immunosuppressive therapy.

Methods: A total of 248 patients with a new diagnosis of ANCA-associated vasculitis were included in this study. The incidence, time, site, and risk factors of severe infection by the induction therapies were analysed. Multivariate Cox proportional hazards models were used to calculate hazard ratios (HRs) with 95\% confidence intervals (Cl).

Results: A total of 103 episodes of severe infection were identified in $86(34.7 \%, 86 / 248)$ patients during a median follow-up of 15 months. The incidence of infection during induction therapy was $38.5 \%$ for corticosteroids (CS), 39.0\% for CS+ intravenous cyclophosphamide (IV-CYC), 33.8\% for CS+ mycophenolate mofetil and 22.5\% for CS + tripterygium glycosides, 76 (73.8\%) infection episodes occurred within 6 months, while 66 (64.1\%) occurred within 3 months. Pneumonia $(71.8 \%, 74 / 103)$ was the most frequent type of infection, and the main pathogenic spectrum included bacteria (78.6\%), fungi (12.6\%), and viruses (8.7\%). The risk factors associated with infection were age at the time of diagnosis $(H R=1.003,95 \% \mathrm{Cl}=1.000-1.006)$, smoking $(\mathrm{HR}=2.338,95 \% \mathrm{Cl}=1.236-4.424)$, baseline secrum creatinine $(\mathrm{SCr}) \geq 5.74 \mathrm{mg} / \mathrm{dl}(\mathrm{HR}=2.153,95 \% \mathrm{Cl}=1.323-3.502), \mathrm{CD} 4^{+} \mathrm{T}$ cell $<281 \mu \mathrm{l}(\mathrm{HR}=1.813,95 \% \mathrm{Cl}=1$. 133-2.900), and intravenous cyclophosphamide regimen ( $\mathrm{HR}=1.951,95 \% \mathrm{Cl}=1.520-2.740)$. Twelve (13.9\%) patients died of severe pneumonia.

Conclusion: The infection rate during induction therapy was high in patients with AAV. Bacterial pneumonia was the main type of infection encountered. Age at the time of diagnosis, smoking, baseline $\mathrm{SCr} \geq 5.74 \mathrm{mg} / \mathrm{dl}, \mathrm{CD} 4^{+} \mathrm{T}$ cell< $281 \mu \mathrm{l}$, and IV-CYC therapy were identified as risk factors for infection.
\end{abstract}

Keywords: Anti-neutrophil cytoplasmic antibody, Vasculitis, Infection, Lung, Risk factors

\section{Background}

Antineutrophil cytoplasmic antibody (ANCA)-associated vasculitis (AAV) is a systemic vasculitis syndrome including microscopic polyangiitis (MPA), granulomatosis with polyangiitis (GPA), eosinophilic granulomatosis with polyangitis (EGPA) and renal-limited vasculitis (RLV). The diagnosis of AAV is based on the presence of clinical manifestations with characteristic histopathological findings and the presence of MPO-ANCA or PR3-ANCA [1-7]. AAV may have predominant involvement of the

\footnotetext{
*Correspondence: gyc_626828@126.com; huwx@vip.163.com ${ }^{\dagger}$ Liu Yang and Honglang Xie contributed equally to this work. National Clinical Research Center of Kidney Diseases, Jinling Hospital, Nanjing
} University School of Medicine, Nanjing 210002, China upper respiratory tract, lungs, kidneys, skin, and nervous system. Most patients with AAV achieved remission after appropriate immunosuppressive therapy with corticosteroids and immunosuppressants, including cyclophosphamide (CYC), mycophenolate mofetil (MMF), and rituximab (RTX) [8-11]. Nevertheless, infection after immunosuppressive therapy contributes to the most common cause of death. The burden of infectious disease in patients with AAV has been reported [1-6, 12-15]. Nonetheless, risk infectors reported so far are inconsistent. In this study, we retrospectively analysed the epidemiological and clinical characteristics of Chinese patients with ANCA-associated vasculitis and discussed major infection episodes occurring during immunosuppressive therapy in a single centre. 


\section{Methods}

\section{Patient selection}

A total of 248 patients newly diagnosed with AAV and renal involvement who met the criteria of the Chapel Hill Consensus Conference [7] between January 1, 1998 and December 31, 2013 at the National Clinical Research Center of Kidney Diseases Jinling Hospital were included, among whom 194 patients had renal biopsies that showed pauci-immune necrotic and crescentic glomerulonephritis. All patients were ANCA-positive. Patients with secondary vasculitis, including Henoch-Schonlein purpura, allergy, autoimmune disease, tumour, cryoglobulinemia and infection, were not included. Patients with end-stage renal disease (ESRD) or who received only non-immunosuppressive treatment for infection at the time of diagnosis of AAV were excluded from the study. Ethical statement: This study was approved by the Institutional Review Board of our hospital and performed in accordance with the ethical standards laid down in appropriate version of the Declaration of Helsinki. All patients signed informed consent.

\section{Clinical and laboratory data}

All clinical and laboratory data were collected retrospectively at diagnosis and during the follow-up period, including the patients' age, gender, medical history, routine blood analysis, 24-h urine protein excretion, urinary sediment red blood cell count, serum albumin and serum creatinine $(\mathrm{SCr})$, liver enzymes, immunoglobulin and $\mathrm{T}$ lymphocyte counts, serum ANCAs, lung involvement, Birmingham Vasculitis Activity Score (BVAS) [16], the usage of immunosuppressive agents, methlyprednisone pulse therapy, plasma exchange, and adverse events including major infection. Major infections were diagnosed according to common terminology criteria for adverse events (CTCAE) v4.0 in addition to clinical and radiological manifestations and microorganism cultures.

\section{Immunosuppressive therapies}

None of the patients had received any immunosuppressive therapy before diagnosis. Patients without contraindication initially received intravenous methylprednisolone pulse therapy ( $0.5 \mathrm{~g}$, once daily, for 3 consecutive days) after diagnosis of AAV. Patients with severe manifestations of AAV underwent plasma exchange therapy. All patients received oral prednisone at a dose of $0.6-0.8 \mathrm{mg} /$ $\mathrm{kg}$ /day for 4 weeks, which was then tapered by $5 \mathrm{mg}$ each week to $10 \mathrm{mg} /$ day. Induction immunosuppressive agents included MMF 1-1.5 g/day orally, monthly intravenous cyclophosphamide (IV-CYC) at $0.75-1.0 \mathrm{~g} / \mathrm{m}^{2}$ body surface area in monthly pulses, tripterygium glycosides (TW, extract from the traditional Chinese herb Tripterygium wilfordii, which mainly contains triptolide) and multi-target therapy (prednisone, mycophenolate mofetil and tacrolimus) [8]. Maintenance therapy included prednisone
$5 \mathrm{mg} /$ day combined with MMF and azathioprine. Prophylaxis of Pneumocystis Jirovecii pneumonia (PJP) with SMZ-CO (trimethoprim-sulfamethoxazole 400/80 $0.48 \mathrm{~g}$ per day) was used in patients whose $\mathrm{CD}^{+}{ }^{+} \mathrm{T}$ cell counts were less than $200 / \mu \mathrm{l}$, and the doses were tapered in patients with renal dysfunction [17].

\section{Antimicrobial therapy}

All immunosuppressive agents, except prednisone, were discontinued in patients with AAV who suffered from major infection during the follow-up period. Antimicrobial therapy was prescribed according to clinical and radiological manifestations and microbiological characteristics. Patients diagnosed with PJP were treated with SMZ-CO and echinocandin together.

\section{Supportive therapy}

Patients with weight loss were prescribed enteral nutrition. The patients with severe acute kidney injury or acute respiratory distress syndrome (ARDS) were treated with continuous blood purification.

\section{Definitions}

A recorded severe infectious complication was defined as implying the administration of an antimicrobial medication for an observable clinical, microbiological and radiologic suspected infection requiring hospitalization. Immediate dialysis was defined as the clinical necessity of renal replacement therapy on admission. The first immunosuppressive agent used in addition to corticosteroids was termed induction therapy. The immunosuppressive regimen used during follow-up was termed the maintenance agent. The diagnosis criteria for deep fungal infection included clinical manifestations, such as fever, cough, diarrhoea or lower urinary tract symptoms, and the detection of fungi in sputum, urine, stool or tissue specimens. Cytomegalovirus (CMV) infection was diagnosed by CMV polymerase chain reaction (PCR). The range of quantification of this assay was 600-100,000 copies/ml for CMV. CMV pneumonia was defined as the detection of ground glass opacity by chest X-ray film or computed tomography, the detection of CMV in the bronchoalveolar lavage fluid or lung tissue samples, and clinical signs such as fever, cough, dyspnoea and hypoxemia. The diagnosis of PJP was made clinically or by the identification of Pneumocystis from sputum, bronchoalveolar fluid, tracheal secretions or lung tissue by special stains or a non-nested PCR, specifically designed to diagnose pneumonia rather than colonization [18]. ARDS was defined as the acute onset of hypoxemia (arterial partial pressure of oxygen to fraction of inspired oxygen $\left[\mathrm{P}_{\mathrm{aO} 2} / \mathrm{F}_{\mathrm{IO} 2}\right] \leq 200 \mathrm{mmHg}$ ) with bilateral infiltrates on chest radiographs, without left atrial hypertension. Multiple organ dysfunction syndrome (MODS) was defined as the simultaneous failure of at 
least two organs. ESRD was defined as eGFR $<15 \mathrm{ml} / \mathrm{min}$ per $1.73 \mathrm{~m}^{2}$ or requiring renal replacement treatment for $>3$ months.

\section{Follow-up and endpoints}

The follow-up endpoints included the final date of December 31, 2014, dropping out before the final date, reaching ESRD, or death.

\section{Statistical analysis}

Statistical analysis was performed with SPSS 20.0 for Windows (SPSS Inc., Chicago, IL, USA). Medians and ranges were reported for non-normally distributed data, and means \pm standard deviations were reported for normal-distributed data. The Kruskal-Wallis test was applied for the comparison of non-normal distributed data. Differences between means were tested using the Student's t-test. A Mann-Whitney U test was used for nonparametric distributions. Chi-squared tests were used for the comparison of categorical data. To address the independent predictive value of factors associated with the rate of infections, the variables with $P$ values of less than 0.1 in univariate analysis as well as those reported in the literature were selected for multivariate analysis using the Cox regression model. The group with corticosteroids only was used as a reference group in multivariate analysis. Only the time to first severe infection was evaluated. Laboratory values and BVAS used for modelling were from the time of diagnosis. Receiver operating characteristic (ROC) curve analysis was performed to determine the cut-offs of $\mathrm{SCr}$, haemoglobin, albumin, CD4+ $\mathrm{T}$ cells and BVAS. All tests were two-tailed, and $P$-values of $<0.05$ were considered significant. Confidence intervals (CIs) were calculated at the $95 \%$ level.

\section{Results}

\section{Characteristics of the cohort}

This study identified 248 individuals with ages ranging from 14 to 78 years (median 55 years), including 214 cases diagnosed as MPA, 16 cases diagnosed as RLV, 10 cases diagnosed as GPA and 8 cases diagnosed as EGPA. Seventy-five patients (30.2\%) showed lung involvement, 30 (12.1\%) had alveolar haemorrhage, and 54 (21.8\%) had sinus involvement. MPO-ANCA was more prevalent, and only 21 cases (8.5\%) were PR3-ANCA-positive. Fifty-three patients started immediate dialysis. Initial immunosuppressive treatment consisted of pulse methylprednisolone $(67.3 \%)$, plasma exchange (23.8\%), IV-CYC (26.6\%), MMF (31.0\%) and TW (16.1\%). Twenty-six percent of patients received only oral corticosteroids (Table 1). Forty-two patients (16.5\%) received SMZ-CO to prevent PJP, and 29 of them were CYC users.

\section{Incidence and location of infection}

A total of 103 infectious episodes occurred in 86 patients (34.7\%) during follow-up for 1 155 months (median 15 months). Fifteen cases experienced a second episode of infection, and one patient experienced a third episode. Seventy-six episodes $(73.8 \%)$ of infection occurred during induction therapy (median 1.5 months). Twenty-seven episodes (26.2\%) occurred during maintenance therapy (median 18 months), and six episodes (5.8\%) occurred after 24 months. Pulmonary infections $(71.8 \%, 74 / 103)$ were the most frequent type of infection, followed by skin $(n=7,6.8 \%)$, digestive tract $(n=3$, $2.9 \%)$, urinary tract $(n=2,1.9 \%)$ and central nervous system $(n=1,1.0 \%)$ infections. Six patients $(5.8 \%)$ developed sepsis because of their reported infection.

\section{Pathogens}

The pathogens responsible for infection were confirmed in 87 episodes. The whole pathogen spectrum included bacteria, fungi and viruses. Bacterial infection was the most common $(n=57,66 \%)$, especially Acinetobacter baumannii, followed by fungal $(n=21,24 \%)$ and viral infections $(n=9,10 \%)$ There were four CMV, seven PJP and 16 unspecified infections (Table 2).

\section{Risk factors for infection}

The infectious rate of induction therapy with corticosteroids only was $38.5 \%(25 / 65)$, that for CS + IV-CYC was $39.0 \%$ (26/66), CS + MMF was $33.8 \%(26 / 77)$ and CS + TW was $22.5 \%(9 / 40)$. The incidence of smoking $(36.0 \%$ vs. $17.3 \%, P=0.000)$ and diabetes $(8.1 \%$ vs. $2.5 \%, P=$ $0.032)$ was significantly higher among the infected patients. The cutoff level of $\mathrm{SCr}$ haemoglobin, albumin, CD4+ T cells, and BVAS were determined as $5.74 \mathrm{mg} / \mathrm{dl}$, $7.75 \mathrm{~g} / \mathrm{dl}, 33.95 \mathrm{~g} / \mathrm{l}, 281 / \mathrm{ul}$, and 25.5 respectively based on ROC curve analysis. Single factor analysis revealed that risk factors for complicated infection in patients with AAV included age, smoking, pulmonary involvement, hemoglobulin, albumin, SCr level, $\mathrm{CD} 4{ }^{+} \mathrm{T}$ cell count, BVAS, and immunosuppressive therapy with MMF, CYC and TW. In adjusted models for the AAV cohort, increased risks of infection were observed in patients who were older at the time of diagnosis $(\mathrm{HR}=$ $1.003,95 \% \mathrm{CI}=1.000-1.006)$, smoking ( $\mathrm{HR}=2.338,95 \%$ $\mathrm{CI}=1.236-4.424)$, with baseline $\mathrm{Scr} \geq 5.74 \mathrm{mg} / \mathrm{dl} \quad(\mathrm{HR}=$ 2.153, 95\% CI $=1.323-3.502), \mathrm{CD}^{+}{ }^{+} \mathrm{T}$ cell $<281 \mu \mathrm{l}(\mathrm{HR}=$ $1.813,95 \% \mathrm{CI}=1.133-2.900$ ), and users of intravenous cyclophosphamide regimen $(\mathrm{HR}=1.951,95 \% \mathrm{CI}=1.520$ 2.740) (Table 3).

\section{Characteristics of pneumonia}

The exact pathogen was identified in 44 of 82 episodes of pneumonia. Bacteria were the most common pathogens $(n=27,61.4 \%)$, especially Acinetobacter baumannii 
Table 1 Clinical characteristics of AAV patients complicated with or without infection

\begin{tabular}{|c|c|c|c|c|}
\hline & $\begin{array}{l}\text { AAV } \\
(n=248)\end{array}$ & $\begin{array}{l}\text { Infection group } \\
(n=86)\end{array}$ & $\begin{array}{l}\text { Non-infection group } \\
(n=162)\end{array}$ & $P$ \\
\hline Age(ys) & $55.0(42.8 \sim 64.0)$ & $58.0(46.8 \sim 66.0)$ & $54.0(40.0 \sim 63.0)$ & 0.082 \\
\hline male, n(\%) & $103(41.5)$ & $40(46.5)$ & $63(38.9)$ & 0.155 \\
\hline smoke, n(\%) & $59(23.8)$ & $31(36.0)$ & $28(17.3)$ & $0.000^{* *}$ \\
\hline Diabetes, n(\%) & $11(4.4)$ & $7(8.1)$ & $4(2.5)$ & $0.032^{*}$ \\
\hline MPO-ANCA, n(\%) & $227(91.5)$ & 79 (91.9) & $148(91.4)$ & 0.968 \\
\hline PR3-ANCA, n(\%) & $21(8.5)$ & $7(8.1)$ & $14(8.6)$ & 0.968 \\
\hline Hemoglobin (g/dl) & $8.5(7.4 \sim 9.7)$ & $8.2(6.7 \sim 9.2)$ & $8.8(7.7 \sim 9.9)$ & $0.004^{* *}$ \\
\hline White blood cell (/mm3) & $\begin{array}{l}7200.0 \\
(5000.0 \sim 10,000.0)\end{array}$ & $\begin{array}{l}7600.0 \\
(5900.0 \sim 11,350.0)\end{array}$ & $\begin{array}{l}6900.0 \\
(4900.0 \sim 9750.0)\end{array}$ & $0.049^{*}$ \\
\hline Albumin $(\mathrm{g} / \mathrm{l})$ & $35.5(31.6 \sim 38.7)$ & $33.8(30.3 \sim 36.9)$ & 35.9 (32.4 39.6) & $0.002^{*}$ \\
\hline Globulin (g/l) & $27.4(23.4 \sim 32.2)$ & $26.8(22.3 \sim 33.1)$ & $27.6(23.5 \sim 31.6)$ & 0.761 \\
\hline Creatinine (mg/dl) & $3.3(1.8 \sim 5.3)$ & $4.16(2.5 \sim 6.9)$ & $2.8(1.5 \sim 4.7)$ & $0.000^{* *}$ \\
\hline eGFR< $60 \mathrm{ml} / \mathrm{min}$ per $1.73 \mathrm{~m}^{2}, \mathrm{n}(\%)$ & $216(87.1)$ & $81(94.2)$ & $135(83.3)$ & $0.000^{* *}$ \\
\hline CD4 lympnocyte cell(/ul) & $416.0(234.5 \sim 589.8)$ & $399.0(207.5 \sim 552.0)$ & $428.0(258.0 \sim 662.0)$ & $0.027^{*}$ \\
\hline $\operatorname{lgG}(g / \operatorname{l})$ & $13.3(10.4 \sim 16.4)$ & $13.4(10.4 \sim 16.5)$ & $12.9(10.3 \sim 16.3)$ & 0.570 \\
\hline C3 (g/l) & $0.9(0.8 \sim 1.1)$ & $0.9(0.8 \sim 1.2)$ & $0.9(0.8 \sim 1.1)$ & 0.569 \\
\hline Lung involvement, n(\%) & $75(30.2)$ & $34(39.5)$ & $41(25.3)$ & $0.011^{* *}$ \\
\hline BVAS & $14(12 \sim 16)$ & $15(12 \sim 17)$ & $14(12 \sim 16)$ & $0.009^{* *}$ \\
\hline MP pulse therapy, $\mathrm{n}(\%)$ & $167(67.3)$ & $56(65.1)$ & $111(68.5)$ & 0.929 \\
\hline Plasma exchanage, n(\%) & $59(23.8)$ & $25(29.1)$ & $34(20.9)$ & 0.109 \\
\hline \multicolumn{5}{|l|}{ Induction therapy } \\
\hline corticosteroids only, n(\%) & $65(26.2)$ & $25(29.1)$ & $40(24.7)$ & 0.349 \\
\hline corticosteroids+CYC, n(\%) & $66(26.6)$ & $26(30.2)$ & $44(27.2)$ & 0.938 \\
\hline corticosteroids+MMF, n(\%) & $77(31.0)$ & $26(30.2)$ & $47(29.0)$ & 0.245 \\
\hline corticosteroids+TW, n(\%) & $40(16.1)$ & $9(10.5)$ & $31(19.1)$ & 0.052 \\
\hline
\end{tabular}

( $n=6,13.6 \%)$, Staphylococcus aureus $(n=5,18.5 \%)$ and Pseudomonas aeruginosa $(n=3,6.0 \%)$. Thirteen cases were diagnosed as fungal infections, and most were caused by $C$. albicans $(n=8,61.5 \%)$. CMV was identified in all four cases with viral pneumonia.

The main pulmonary radiologic findings included consolidation $(n=38,51.4 \%)$, diffuse interstitial pneumonia $(n=21,28.4 \%)$ and multiple nodules $(n=13$, $17.6 \%)$. Bacterial pneumonia presented with consolidation $(n=24,32.4 \%)$, nodules $(n=9,12.2 \%)$ and a diffuse reticular pattern $(n=6,8.1 \%)$. CMV pneumonia mainly presented with ground-glass opacities (4, $5.4 \%)$, diffuse reticular thickening $(n=3,4.1 \%)$ and nodules $(n=1,1.4 \%)$ on bilateral lungs. Fungal pneumonia was characterized by consolidation $(n=14$, $18.9 \%)$, nodules $(n=4,5.4 \%)$, halo $(n=4,5.4 \%)$ and air crescent sign $(n=2,2.7 \%)$. Thirteen cases were complicated by ARDS, and 10 were complicated by MODS. Nine patients required mechanical respiration (5 BiPAP and 4 endotracheal intubation).

\section{Treatment and outcome of infectious episodes}

All 103 episodes were treated with intravenous antibiotics. Twelve (11.7\%) of 103 patients died and all due to severe pneumonia. The time to death was from one to sixteen months after the initiation of immunosuppressive therapy. None died due to AAV (Table 4).

\section{Discussion}

A link between vasculitis and infection has long been suspected. Bacterial infections can trigger the production of various autoantibodies, including ANCA [19]. Infection is a major concern in the management of AAV and is the most common cause of death, especially in patients with malnutrition or immunosuppressive therapy [1-3]. Immunosuppressive therapy is performed with consideration of the disease activity, which is comprehensively evaluated based on the BVAS score [20]. Nonetheless, even in patients with severe ANCA-associated vasculitis, secondary infection, rather than active AAV, is the leading cause of death [21]. There still remains no firm 
Table 2 Pathogens of infection

\begin{tabular}{|c|c|c|}
\hline & Pathogens $(n=87)$ & N (\%) \\
\hline \multirow[t]{15}{*}{ Bacterium } & Acinetobacter baumannii & $6(7)$ \\
\hline & Staphylococcus aureus & $5(6)$ \\
\hline & Pseudomonas aeruginosa & $3(4)$ \\
\hline & Escherichia coli & $2(2)$ \\
\hline & Klebsiella pneumoniae & $2(2)$ \\
\hline & Neisseria & $2(2)$ \\
\hline & M.tuberculosis & $2(2)$ \\
\hline & Viridans Streptococci & $1(1)$ \\
\hline & Streptococcus & $1(1)$ \\
\hline & Salmonella enteritidis & $1(1)$ \\
\hline & CitrobacterWerkmanandGillen & $1(1)$ \\
\hline & A.juniiBouvetandGrimont & $1(1)$ \\
\hline & Stenotrophomonas maltophilia & $1(1)$ \\
\hline & Enterobacter cloacae & $1(1)$ \\
\hline & Nonspecific infection & $28(32)$ \\
\hline \multirow[t]{4}{*}{ Fungus } & C.albicans & $9(11)$ \\
\hline & Pneumocystis jiroveci & $7(8)$ \\
\hline & Aspergillus fumigatus & $3(4)$ \\
\hline & Candida tropicalis & $2(2)$ \\
\hline \multirow[t]{2}{*}{ Virus } & Varicella-zoster virus & $5(6)$ \\
\hline & Cytomegalovirus & $4(5)$ \\
\hline
\end{tabular}

conclusion about the burden and characteristics of major infections in patients with AAV.

We retrospectively reviewed the clinical charts of 248 Chinese patients with AAV. Major infections were reported in $34.6 \%$ of our single-centre cohort. Approximately $64.1 \%$ of these infections developed in the first three months of induction therapy. In the reported studies, corticosteroids contributed to $89 \%$ of infections of patients with AAV, and the infection rate decreased when the corticosteroids were tapered [1-4]. Corticosteroid treatment leads to an immunocompromised status in patients by inhibiting cytokines, neutrophils, and immunologic response and by exerting anti-inflammatory and immunosuppressive effects [22]. Infection is suspected when fever $\left(\geq 37.3{ }^{\circ} \mathrm{C}\right)$ persists for no less than three days and $\mathrm{C}$-reactive protein increases after remission of AAV [22]. The evaluation of infection is based on the presence of organ manifestations. Identificating methods of causative microorganisms, such as common bacteria, viruses, and fungi, include mycological, histological, and genetic tests [20].

The main areas of infection included the lungs and skin. The lung infection rate was as high as $79.6 \%$ in this cohort. Most AAV patients had impaired renal function, and lung involvement and diffuse alveolar haemorrhage injure the local protective barrier. Renal injury also increases the risk of severe infection and is closely associated with a poor outcome $[6,18]$. According to the literature, the most common causative pathogens are bacteria, such as Streptococcus pneumonia and Haemophilus influenza [23, 24], followed by fungi and viruses. In our cohort, the main bacteria included Acinetobacter baumannii, Staphylococcus aureus, and Pseudomonas aeruginosa (Table 2), and our rates of infections with fungi and viruses were higher and lower, respectively, than those of previous reports [25]. Characteristics of AAV, such as global inflammation, renal injury, lung involvement, malnutrition, and immunosuppressive therapy, contribute to infections by opportunistic pathogens [26]. CMV, PJP and 13 cases of pneumomycosis developed during induction therapy. It is also possible that a PJP diagnosis may have been

Table 3 COX regression for AAV complicated infection

\begin{tabular}{|c|c|c|c|c|}
\hline \multirow[b]{2}{*}{ varium } & \multicolumn{2}{|l|}{ Single factor analysis } & \multicolumn{2}{|c|}{ Multiple factor analysis } \\
\hline & $\mathrm{HR}(95 \% \mathrm{Cl})$ & $P$ & $\mathrm{HR}(95 \% \mathrm{Cl})$ & $P$ \\
\hline Age & $1.004(1.001-1.007)$ & 0.008 & $1.003(1.000-1.006)$ & 0.030 \\
\hline gender & $1.444(0.938-2.221)$ & 0.095 & $0.723(0.394-1.328)$ & 0.296 \\
\hline smoking & $2.293(1.465-3.588)$ & 0.000 & $2.338(1.236-4.424)$ & 0.009 \\
\hline Diabetes & $1.504(0.651-3.474)$ & 0.339 & & \\
\hline Hemoglobin $<7.75 \mathrm{~g} / \mathrm{dl}$ & $2.079(1.358-3.182)$ & 0.001 & $1.362(0.827-2.243)$ & 0.224 \\
\hline Albumin $<33.95 \mathrm{~g} / \mathrm{l}$ & $1.902(1.243-2.910)$ & 0.003 & $1.178(0.740-1.874)$ & 0.490 \\
\hline baseline creatinine higher than 5.74 mg/dl & $3.190(2.053-4.957)$ & 0.000 & $2.153(1.323-3.502)$ & 0.002 \\
\hline $\mathrm{CD}^{+}{ }^{\top} \mathrm{T}$ cell $<281 / \mathrm{ul}$ & $02.021(1.316-3.105)$ & 0.001 & $1.813(1.133-2.900)$ & 0.013 \\
\hline BVAS at the time of diagnosis $>25.5$ & $1.883(0.815-4.349)$ & 0.138 & & \\
\hline corticosteroids+MMF & $1.945(1.156-3.272)$ & 0.012 & $1.004(0.571-1.765)$ & 0.989 \\
\hline corticosteroids+CYC & $1.906(1.073-3.383)$ & 0.028 & $1.951(1.520-2.740)$ & 0.042 \\
\hline corticosteroids+TW & 1.519 (1.110-2.715) & 0.042 & $0.572(0.262-1.250)$ & 0.161 \\
\hline
\end{tabular}

MP Methlyprednisone, MMF mycophenolate mofetil, CYC cyclophosphamide, TW Tripterygium wilfordii 
Table 4 ESRD and Death

\begin{tabular}{lll}
\hline & $\begin{array}{l}\text { Infection } \\
\text { group }\end{array}$ & $\begin{array}{l}\text { Non-infection } \\
\text { group }\end{array}$ \\
\hline ESRD & 21 & 13 \\
Time to ESRD, (months) & $2.5(1 \sim 7)$ & $12(5 \sim 32.5)$ \\
Death & 12 & 0 \\
Time to Death, (months) & $3(2 \sim 12)$ & \\
Cause of Death & & \\
Acinetobacter baumannii & 1 & \\
Staphylococcus aureus & 1 & \\
Stenotrophomonas maltophilia & 1 & \\
C.albicans & 1 & \\
Pneumocystis jiroveci & 1 & \\
Aspergillus fumigates & 1 & \\
Nonspecific infection & 1 & \\
\hline
\end{tabular}

ESRD end-stage renal disease

missed, especially earlier in the study period when our microbiology laboratory used Pneumocystis stains. Some clinical studies have concluded that Streptococcus pneumonia and influenza vaccines are safe and effective [27-29]. Thus, improving the vaccination coverage against streptococcus pneumonia and influenza in high-risk populations could play an important role in pulmonary prevention [30].

The most common computed tomography findings were ground-glass attenuation, reticular pattern, and fibrous bands with infiltration. In cases of bacterial, fungal and viral pneumonia, a consolidation and reticular pattern, patchy consolidation and glass-ground attenuation were most commonly observed, respectively. These characteristics are predominantly seen in pneumonia patients with AAV.

Given the high incidence of infections in patients with AAV, risk factors need to be defined in order to increase surveillance and prescribe prophylactic antibiotic therapy. Many studies have reported that age, female gender, diabetes, impaired renal function, clinical grade category of rapidly progressive glomerulonephritis (RPGN), lymphopenia and immunosuppressive therapy are risk factors for infection in AAV [6, 12-14, 20, 31]. However, there remains no consensus about the infectious risk factors in Chinese patients with AAV. In this cohort, BVAS and the frequency of diabetes in the infectious group were higher than that in the control group, indicating that higher BVAS and diabetes are potential risk factors of infection. Age at the time of diagnosis $(\mathrm{HR}=1.003$, 95\% $\mathrm{CI}=1.000-1.006)$, smoking $(\mathrm{HR}=2.338,95 \% \mathrm{CI}=$ 1.236-4.424), baseline Scr $\geq 5.74 \mathrm{mg} / \mathrm{dl}(\mathrm{HR}=2.153,95 \%$ $\mathrm{CI}=1.323-3.502), \mathrm{CD}^{+}{ }^{+} \mathrm{T}$ cell $<281 \mathrm{ul}(\mathrm{HR}=1.813,95 \%$ $\mathrm{CI}=1.133-2.900)$, and use of intravenous CYC were independent risk factors of infection. Whether or not the use of CYC was a risk factor for developing infection in AAV patients remains controversial $[9,10,14]$. Masaharu [20] also reported that the use of CYC was a risk factor for developing infection in AAV patients, but no difference was observed in renal failure between those with or without infection. On the other hand, CYC showed similar adverse events when compared to Rituximab in two randomized controlled trials $[9,10]$.

In our study, the infection-related mortality (11.7\%) was less than that reported in most of the literatures $[4,13,14,32]$. Half of these cases died within the first month after diagnosis. Thus, clinicians should consider adaptive immunosuppressive agents to avoid life-threatening infection.

\section{Limitations}

There are some limitations in this retrospective study. First, the treatment protocols were not uniform and lack of data on Rituximab. Only a minority of patients were given SMZ-CO prophylaxis because of the insufficient awareness. None of these patients received prophylaxis for fungal infection. In addition, some cases with pulmonary or central nervous system infection failed to show a definitive pathogen. The frequency and severity of pneumonia should be lowered by prophylactic treatment and early diagnosis.

\section{Conclusion}

Infections can develop during every stage of AAV, primarily in the lungs and skin. The pathogens identified in this study mainly consisted of bacteria, candidiasis, CMV and herpes simplex virus, and age at the diagnosis, smoking, baseline SCr higher than $5.74 \mathrm{mg} / \mathrm{dl}, \mathrm{CD}^{+}{ }^{+} \mathrm{T}$ cell<281 $\mu \mathrm{l}$, and CYC therapy were independent risk factors for infection in patients with AAV.

\begin{abstract}
Abbreviations
AAV: Antineutrophil cytoplasmic antibody -associated vasculitis; ANCA: Antineutrophil cytoplasmic antibody; ARDS: Acute respiratory distress syndrome; BVAS: Birmingham Vasculitis Activity Score; Cl: Confidence intervals; CMV: Cytomegalovirus; CS: Corticosteroids; CTCAE: Common terminology criteria for adverse events; CYC: Cyclophosphamide; EGPA: Eosinophilic granulomatosis with polyangitis; ESRD: End-stage renal disease; GPA: Granulomatosis with polyangiitis; HRs: Hazard ratios; IV-CYC: Intravenous cyclophosphamide; MMF: Mycophenolate mofetil; MODS: Multiple organ dysfunction syndrome; MPA: Microscopic polyangiitis; PCR: Polymerase chain reaction; PJP: Pneumocystis Jirovecii pneumonia; RLV: Renal-limited vasculitis; ROC: Receiver operating characteristic; RTX: Rituximab; SCr: Secrum creatinine; SMZ-CO: trimethoprimsulfamethoxazole 400/80; TW: Tripterygium glycosides
\end{abstract}

\section{Acknowledgements}

We acknowledge Dr. Le Weibo for the assistance of statistic analysis. We appreciated all the participants for their contribution to this study.

\section{Funding}

This study was supported by National Key Research and Development Program of China (2016YFC0904100). 


\section{Availability of data and materials}

The dataset used and analysed during the current study is not publicly available due to patient-related confidentiality, but it is available from the corresponding author on reasonable request.

\section{Author's contributions}

YL, XHL, LZZ, CYH, WJQ, GYC, ZHT, HWX: contributed to the design of study, performed the data collection and interpretation. $Y L$ and $X H L$ wrote the first draft. LZZ, CYH, WJQ, ZHT, GYC and HWX revised the manuscript. All authors are accountable for all aspects of the work and have approved the final manuscript.

\section{Ethics approval and consent to participate}

This study was approved by Ethics Committee of Jinling Hospital (Nanjing, China). Written consent was obtained from each participant. Declaration of Helsinki was followed while conducting this analysis.

\section{Consent for publication}

Not applicable

\section{Competing interests}

The authors declare that they have no competing of interests.

\section{Publisher's Note}

Springer Nature remains neutral with regard to jurisdictional claims in published maps and institutional affiliations.

\section{Received: 6 October 2017 Accepted: 25 May 2018}

\section{Published online: 14 June 2018}

\section{References}

1. Charlier C, Henegar C, Launay O, Pagnoux C, Berezne A, Bienvenu B, et al. Risk factors for major infections in Wegener granulomatosis: analysis of 113 patients. Ann Rheum Dis. 2009;68(5):658-63.

2. Reinhold-Keller E, Beuge N, Latza U, de Groot K, Rudert H, Nolle B, et al. An interdisciplinary approach to the care of patients with Wegener's granulomatosis-long-term outcome in 155 patients. Arthritis Rheum. 2000;43(5):1021-32.

3. Gavraud M, Guillevin L, Le Toumelin P, Cohen P, Lhote F, Casassus P, et al. Long-term followup of polyarteritis nodosa, microscopic polyangiitis, and Churg-Strauss syndrome. Analysis of four prospective trials including 278 patients. Arthritis Rheum. 2001;44(3):666-75.

4. Flossmann O, Berden A, de Groot K, Hagen C, Harper L, Heijl C, et al. Long term patient survival in ANCA-associated vasculitis. Ann Rheum Dis. 2011: 70(3):488-94.

5. Mukhtyar C, Guillevin L, Cid MC, Dasgupta B, de Groot K, Gross W, et al. EULAR recommendations for the management of primary small and medium vessel vasculitis. AnnRheum Dis. 2009:68(3):310-7.

6. Harper L, Savage CO. ANCA-associated renal vasculitis at the end of the twentieth century-a disease of older patients. Rheumatology. 2005:44(4): 495-501.

7. Jennette JC, Fallc RJ, Andrassy K, Bacon PA, Churg J, Gross WL, et al. Nomenclaure of systemic vasculitides: the proposal of an international consensus conference. Arth Rheum. 1994;37(2):187-92.

8. Hu W, Liu C, Xie H, Chen H, Liu Z, Li L. Mycophenolate mofetil versus cyclophosphamide for inducing remission of ANCA vasculitis with moderate renal involvement. Nephrol Dial Transplant. 2007;23(4):1307-12.

9. Jones RB, Tervaert JW, Hauser T, Luqmani R, Morgan MD, Peh CA, et al. Rituximab versus cyclophosphamide in ANCA-associated renal vasculitis. N Engl J Med. 2010;363(3):211-20.

10. Stone JH, Merkel PA, Spiera R, Seo P, Langford CA, Hoffman GS, et al. Rituximab versus cyclophosphamide for ANCA-associated renal vasculitis. N Engl J Med. 2010;363(3):221-32.

11. Guillevin L, Pagnoux C, Karras A, Khouatra C, Aumaitre O, Cohen P, et al. Rituximab versus azathioprine for maintenance in ANCA-associated vasculitis. N Engl J Med. 2014;371(19):1771-80.

12. Kronbichler A, Jayne DR, Mayer G. Frequency, risk factors and prophylaxis of infection in ANCA-associated vasculitis. Eur J Clin Investig. 2015:45(3):346-68.

13. McGregor JC, Negrete-Lopez R, Poulton CJ, Kidd JM, Katsanos SL, Goetz L, et al. Adverse events and infectious burden, microbes and temporal outline from immunosuppressive therapy in antineutrophil cytoplasmic antibody- associated vasculitis with native renal function. Nephrol Dial Transplant. 2015:30(Supp|1):i171-81.

14. Kitagawa K, Furuichi K, Sagara A, Shinozaki Y, Kitajima S, Toyama T, et al. Risk factors associated with replapse or infectious complications in Japanese patients with microscopic polyangiitis. Clin Exp Nephrol. 2016;20(5):703-11.

15. Mohammad AJ, Segelmark M, Smith R, Englund M, Nilsson JA, Westman K, et al. Severe infection in antineutrophil cytoplasmic antibody-associated vasculitis. J Rheumatol. 2017;44(10):1468-75.

16. Flossmann $O$, Bacon $P$, de Groot $K$, Jayne D, Rasmussen N, Seo P, et al. Development of comprehensive disease assessment in systemic vasculitis. Ann Rheum Dis. 2007:66(3):283-92.

17. Katsuyama T, Saito K, Kubo S, Nawata M, Tanaka Y. Prophylaxis for pneumocystis pneumonia in patients with rheumatoid arthritis treated with biologics, based on risk factors found in a retrospective study. Arthritis Res Ther. 2014;16:R43.

18. Wilson JW, Limper AH, Grys TE, Karre T, Wengenack NL, Binnicker MJ. Pneumocystis jirovecii testing by real-time polymerase chain reaction and direct examination among immunocompetent and immunosuppressed patient groups and correlation to disease specificity. Diagn Microbiol Infect Dis. 2011;69(2):145-52.

19. Konstantinov KN, Ulff-Moller CJ, Tzamaloukas AH. Infections and antineutrophil cytoplasmic antibodies: triggering mechanisms. Autoimmun Rev. 2015;14(3): 201-3.

20. Haris Á, Polner K, Arányi J, Braunitzer H, Kaszás I, Rosivall L, et al. Simple, readily available clinical indices predict early and late mortality among patients with ANCA-associated vasculitis. BMC Nephrol. 2017;18:76.

21. Li ZY, Ma TT, Chen M, Zhao MH. The prevalence and management of antineutrophil cytoplasmic antibody-associated vasculitis in China. Kidney Dis(Basel). 2016;1(4):216-23.

22. Yoshida M. Strategy of infection control in immunosuppressive therapy for ANCA-associated vasculitis. Ann Vasc Dis. 2013:6(1):9-15.

23. Bonaci-Nikolic B, Andreievic S, Pavlovic M, Dimcic Z, Ivanovic B, Nikolic M. Prolonged infections associated with antineutrophil cytoplasmic antibodies specific to proteinase 3 and myeloperoxidase: diagnostic and therapeutic challenge. Clin Rheumatol. 2010;29(8):893-904

24. Koselj-Kajtna M, Koselj M, Rott T, Kandus A, Bren A. Infectious complications of immunosuppressive treatment for anti-neutrophil cytoplasm antibodyrelated vasculitis. Transplant Proc. 2002:34(7):3001-2.

25. Moosig F, Holle JU, Gross WL. Value of anti-infective chemoprophylaxis in primary systemic vasculitis: what is the evidence? Arthritis Res Ther. 2009; $11(5): 253$.

26. Sowden E, Carmichael AJ. Autoimmune inflammatory disorders, systemic corticosteroids and pneumocystis pneumonia: a strategy for prevention. BMC Infect Dis. 2004:4:42.

27. Stassen PM, Sanders JS, Kallenberg CG, Stegeman CA. Influenza vaccination dose not result in an increase in relapses in patients with ANCA-associated vasculitis. Nephrol Dial Transplant. 2008;23(2):654-8.

28. Holvast A, Stegeman CA, Benne CA, Huckriede A, Wilschut JC, Palache AM, et al. Wegener's granulomatosis patients show an adequate antibody response to influenza vaccination. Ann Rheum Dis. 2009;68(6):873-8.

29. Van Assen S, Agmon-Levin N, Elkayam O, Cervera R, Doran MF, Dougados M, et al. EULAR recommendations for vaccination in adult patients with autoimmune inflammatory rheumatic diseases. Ann Rheum Dis. 2011; 70(3):414-22.

30. Launay O. Improving the vaccination coverage against influenza and streptococcus pneumonia in the populations at risk: the role of pulmonary care services. Rev Mal Respir. 2013;30(9):741-2.

31. Ozaki S, Atsumi T, Hayashi T, Ishizu A, Kobayashi S, Kumagai S, et al. Severitybased treatment for Japanese patients with MPO-ANCA-associated vasculitis: the JMAAV study. Mod Rheumatol. 2012;22(3):394-404.

32. Wall N, Harper L. Complications of long-term therapy for ANCA-associated systemic vasculitis. Nat Rev Nephrol. 2012;8(9):523-32. 